University of Nebraska - Lincoln

DigitalCommons@University of Nebraska - Lincoln

Publications, Agencies and Staff of the U.S.

Department of Commerce

U.S. Department of Commerce

2009

Sex change and the genetic structure of marine fish populations

Julien Chopelet

University College Dublin, julien.chopelet@ucd.ie

Robin Waples

NOAA, robin.waples@noaa.gov

Stefano Mariani

University College Dublin, stefano.mariani@ucd.ie

Follow this and additional works at: https://digitalcommons.unl.edu/usdeptcommercepub

Chopelet, Julien; Waples, Robin; and Mariani, Stefano, "Sex change and the genetic structure of marine fish populations" (2009). Publications, Agencies and Staff of the U.S. Department of Commerce. 456. https://digitalcommons.unl.edu/usdeptcommercepub/456

This Article is brought to you for free and open access by the U.S. Department of Commerce at DigitalCommons@University of Nebraska - Lincoln. It has been accepted for inclusion in Publications, Agencies and Staff of the U.S. Department of Commerce by an authorized administrator of DigitalCommons@University of Nebraska - Lincoln. 


\title{
Sex change and the genetic structure of marine fish populations
}

\author{
Julien Chopelet ${ }^{1}$, Robin $S$ Waples ${ }^{2}$ E Stefano Mariani ${ }^{1}$ \\ ${ }^{1}$ Marine Biodiversity Ecology \& Evolution, UCD School of Biology \& Environmental Science, University College Dublin, \\ Belfield, Dublin 4, Ireland; ${ }^{2}$ Northwest Fisheries Science Center, NOAA Fisheries, 2725 Montlake Blvd. East, Seattle, \\ WA 98112-2097, USA
}

\begin{abstract}
The interaction between environmental forces and dispersal characteristics is largely responsible for the patterns of population structure in marine fish. Yet, crucial gaps in knowledge on life-histories and the relative contributions of numerous environmental factors still hinder a thorough understanding of marine population connectivity. One life-history trait so far overlooked by most fish population geneticists is sequential hermaphroditism, whereby individuals first mature as one sex and later in life reverse into the other sex. Population genetic theory predicts that sex-changing fish will present a higher potential for more spatially structured populations than gonochoristic species, as a result of their naturally skewed sex ratio, which is expected to reduce effective population size and hence increase genetic drift. We gathered published data on genetic population structure in marine fish, as summarized by the popular $F_{\mathrm{ST}}$ index, and - after controlling for several potentially confounding factors - we tested the hypothesis that sex-changing species are more genetically structured than gonochoristic ones. Although we found no evidence to support the theoretical expectations, our results suggest new working hypotheses that can stimulate new research avenues at the intersection between physiology, genetics and fisheries science.
\end{abstract}

Keywords Effective population size, hermaphroditism, life-history, population connectivity, random genetic drift, reproductive strategies

\author{
Correspondence: \\ Stefano Mariani, UCD \\ School of Biology \& \\ Environmental \\ Science, University \\ College Dublin, Bel- \\ field, Dublin 4, Ireland \\ Tel.: +35317162347 \\ Fax: +35317161153 \\ E-mail: stefano. \\ mariani@ucd.ie \\ Received 25 Aug \\ 2008 \\ Accepted 20 Mar \\ 2009
}

Factors affecting population structure in marine fish 330

Effective population size and sex change $\quad 331$

Materials and methods $\quad 332$

Data collection $\quad 332$

$\begin{array}{ll}\text { Data analysis } & 333\end{array}$

$\begin{array}{lr}\text { Results } & 334\end{array}$

Effect of sampling effort and species dispersal ability 334

Testing the hypothesis: do sex-changing species show higher $F_{\mathrm{ST}}$ ? 335

Discussion $\quad 335$

$\begin{array}{ll}\text { Acknowledgements } & 339\end{array}$

$\begin{array}{lr}\text { References } & 339\end{array}$ 


\section{Introduction}

A major goal of modern fisheries research is to acquire knowledge on spatial and temporal genetic variation, thereby yielding information on stock subdivision, genetic depletion, and the capacity of populations to cope with environmental changes (Palsboll et al. 2007; Schwartz et al. 2007). Over the past three decades, most genetic studies of marine fish have focused on gene flow, suggesting that patterns of spatial genetic variation result from interactions between environmental forces and the dispersal characteristics of species, and that these interactions occur over various time scales. In particular, comparative studies (Waples 1987; Doherty et al. 1995) have shown that a significant component of genetic structuring in marine fish is related to species' life-history traits. Nevertheless, population structure can be affected by a variety of other factors, and it is only by taking these carefully into account that the challenge of understanding population connectivity can be met. Here we aim to contribute to such understanding by exploring one previously understudied life-history trait: sequential hermaphroditism.

\section{Factors affecting population structure in marine fish}

Even in the seemingly continuous marine environment, physical barriers may reduce or prevent gene flow. At large scales, phylogeographical structure has been shown to exist as a result of the historical separation of different ocean basins and persistent oceanographical constraints. For example, many marine fish exhibit strong genetic differentiation between the Atlantic and the Mediterranean Sea (Bargelloni et al. 2003; Brutto et al. 2004; Nakadate et al. 2005; and see review in Patarnello et al. 2007). Other well-known phylogeographical breaks include the separation between the Gulf of Mexico and the Western Atlantic (Gold and Richardson 1998; Blandon et al. 2001), the Indian Ocean and the Western Pacific separated by the Torres Strait (Chenoweth et al. 1998) and, within the Pacific Ocean, the Eastern Pacific barrier (Rosenblatt and Waples 1986; Lessios and Robertson 2006) and the disjunction between Gulf of California and Pacific populations (Bernardi et al. 2003). At smaller scales, the topography of the environment and its heterogeneity may also act as an efficient barrier to dispersal at different life-history stages (Bernardi 2000; Riginos and Nachman 2001; Watts and Johnson 2004, Sarvas and Fevolden 2005).

Despite the existence of such physical barriers, several studies have observed contrasting patterns of spatial genetic variation in different species living across the same geographical breaks (Bonhomme et al. 2002; Bargelloni et al. 2003), suggesting that additional variables are important in determining population structure. On the one hand, it has been shown that differences in lifehistory traits, such as pelagic larval duration, adult migratory behaviour, maximum adult size, and egg type, all determine variation in dispersal and hence gene flow (Doherty et al. 1995; Shulman and Bermingham 1995; Riginos and Victor 2001; Bernardi and Vagelli 2004; Bay et al. 2006; Pindaro et al. 2006). On the other hand, differences in genetic patterns of species sharing the same geographical range can often be explained by past historical events. For instance, two populations might exhibit low genetic differentiation if their separation is recent, and with insufficient time for genetic drift to occur. Many examples illustrate the effect of isolation and secondary contacts due to ancient historical events, such as glaciations (Nesbo et al. 2000; Hickerson and Ross 2001; Bernardi et al. 2003; Gysels et al. 2004a,b; Wilson 2006), sea level fluctuations (Planes and Doherty 1997; Stefanni and Thorley 2003; Stefanni et al. 2003; Rohfritsch and Borsa 2005; Van Herwerden et al. 2006) and more generally, climate change (Grant and Bowen 1998; Lecomte et al. 2004).

When gene flow is sufficiently reduced for long periods between two populations exposed to different environmental dynamics, natural selection can also induce strong genetic divergence. Differences in salinity (Lemaire et al. 2000; Nielsen et al. 2004; Cimmaruta et al. 2005), temperature (Borsa et al. 1997; Riginos and Nachman 2001), and biotic characteristics such as predation pressure (Planes and Romans 2004) or zooplankton productivity and feeding activity (Roldan et al. 2000) can affect population structure, if measured using adaptive markers. Furthermore, several studies have explored environmental selection and genetic divergence in the presence of gene flow: although it is generally assumed that gene flow will swamp local adaptation in new environments (Bridle and Vines 2007), recent developments have shown how genetic divergence measured at marker loci under 
hitch-hiking selection is much greater than that measured at neutral loci (Nielsen et al. 2006; Williams and Oleksiak 2008). Several studies seem to confirm that natural selection is a non-negligible force in determining genetic divergence, even in the face of gene flow, at least in coastal and shelf habitats (Beheregaray and Sunnucks 2001; Byers and Pringle 2006; Hemmer-Hansen et al. 2007a; Pringle and Wares 2007).

\section{Effective population size and sex change}

Gene flow is traditionally expressed by the effective number of migrants $\left(N_{\mathrm{e}} m\right)$ per generation, and its value is given by the product of the effective population size, $N_{\mathrm{e}}$, and the migration rate, $m$. Wright's (1951) classical n-island model of population structure and many simulation studies indicate that genetic structuring (as measured by $F_{\text {ST }}$ ) is inversely related to $N_{\mathrm{e}} m$.

Contrary to what has long been assumed, recent studies suggest that surprisingly low effective population sizes are not uncommon in marine fish, despite their large census population size $(N)$ (Hauser et al. 2002; Turner et al. 2002; Hutchinson et al. 2003; Hoarau et al. 2005), with estimates of the $N_{\mathrm{e}} / \mathrm{N}$ ratio ranging between $10^{-3}$ and $10^{-5}$ in several continental shelf fish species belonging to various families (Sciaenidae, Sparidae, Serranidae, Gadidae, Pleuronectidae) (Hauser and Carvalho 2008). High variance in individual reproductive success has been proposed to be one of the potential factors responsible for the relatively low $\mathrm{Ne} / \mathrm{N}$ ratios in some marine fish. In such circumstances, a few individuals can in principle often replace the entire population at the next generation; such 'sweepstakes' events increase the chances that offspring might share the same parent, and the probability that two alleles drawn at random in the population are the same (Hedgecock 1994).

The diversity of reproductive modes in fishes has attracted interest for many decades. In particular, and contrary to all other vertebrates, hermaphroditism is widespread in fish, being in the vast majority of cases, sequential (Warner 1988a), with individuals first maturing as one sex and later in life reversing to the other sex. Sex change has evolved independently in at least 23 teleost families and more than 350 species (Frisch 2004), and yet, our understanding of the evolutionary history of this phenomenon is far from complete (Price 1984;
Devlin and Nagahama 2002; Frisch 2004; Nagahama 2005; Volff 2005). Recently, Sadovy \& Liu (2008) suggested that a 'proto-hermaphroditic' condition is most likely to have been a very ancestral state in fish, providing a platform for the independent evolution of functional hermaphroditism in several fish lineages.

Warner's (1975, 1988b) size-advantage model states that as individuals reach larger sizes, sex change is advantageous if the genetic contribution to the next generation from the 'second' sex is higher than that of the 'first' sex. This model predicts that sex change should occur at a relatively constant size, which was recently shown to be c. $70-80 \%$ of maximum length (Allsop and West 2003). However, the idea that sex change is only determined by size and age has been criticized (Shapiro 1984; Nee et al. 2005). Large intra-population variation has been found in the life stage at which sex change occurs. It has been shown - both in captivity and in the wild - that hermaphroditic fish might not change sex when isolated, and that in some species, sex change depends on the proportion of individuals of the same gender present in the population at any given time (Beentjes and Carbines 2005; Munday et al. 2006).

Contrary to general assumptions, there is strong evidence that sex ratios in sequentially hermaphroditic species are very skewed and biased towards the sex at which individuals first reach reproductive maturity. Allsop and West (2004) analysed data from 121 sex changing species (76 of which were fish, belonging to eight families), and found that their sex ratios significantly departed from $1: 1$, with protandrous (first maturing as males) being malebiased, and protogynous (first maturing as females) being female-biased. Furthermore, Garratt (1985) observed that male:female ratios in Chysoblephus puniceus, a commercially valuable South African protogynous species, are consistently biased towards the females, and ratios can become extremely skewed in heavily exploited populations (over $90 \%$ of the catch being represented by females).

In such a scenario, the mating system is typically characterized by only a few, older and larger individuals of the second sex monopolizing access to other younger and smaller individuals of the first sex. In sex-changing fish, individuals of the lessnumerous second sex still contribute half of the genes in the next generation, hence reducing the number of possible genotypic combinations avail- 
able to the offspring. Such skewed sex ratio is known to reduce the effective size in natural populations (Hartl and Clark 1997). Consequently - all else being equal - it might be expected that sexchanging fish will present a higher potential for exhibiting more spatially structured populations than gonochorists, as a result of lower effective size and increased genetic drift. Such a scenario may be more likely than hitherto expected, as indicated by the higher incidence of adaptive differentiation in marine fishes, and presumed opportunities for isolation, even at small spatial scales (Hauser and Carvalho 2008).

No studies have so far addressed the population genetic consequences of sex change in marine fish. However, many of these species are subjected to harvesting, and in particular, sex-changing Sparids (sea breams), Serranids (groupers), Scarids (parrotfish) and Lethrinids (emperors) all sustain valuable fisheries in both temperate and tropical seas. Fishing pressure has already been shown to exert a sizeselective force on natural populations through the removal of the largest individuals, significantly influencing in some cases the species phenotypic evolution (Kuparinen and Merila 2007). In sexchanging fish, because larger and older individuals mostly belong to one sex, size-selective harvesting will inevitably result in a 'sex-selective' pressure (Alonzo and Mangel 2004, Hawkins and Roberts 2004; Molloy et al. 2007), promoting even more skewed sex ratios (Garratt 1985) and theoretically a pronounced reduction of effective population size.

To test whether sex change can affect the levels of population structure in marine fish, it is necessary to take into account several factors that might bias the comparison between hermaphrodites and gonochoristic species. We have illustrated briefly how the wide diversity of species life-histories and habitats can affect population structure; furthermore, methodological variables, such as the use of genetic markers with different characteristics (i.e. nuclear vs. mitochondrial; fast-evolving vs. slowevolving; neutral vs. adaptive) (Avise 2004), as well as the number of markers employed, the sample size and the number of populations screened (Waples 1998; Slatkin 2005; Ryman et al. 2006) can also influence estimates of genetic structuring among populations.

Here we present the results of an extensive survey comparing data from hundreds of population genetic studies on marine fish, including both protogynous and protandrous sequential hermaph- rodites, as well as gonochoristic species. After accounting for other ecological and methodological variables, we tested the null hypothesis that there is no significant difference in the level of population genetic structuring between the groups.

\section{Materials and methods}

\section{Data collection}

Data on population genetic structure were obtained from published articles (from 1987 to 2007) using two databases: ISI Web of Science and the Aquatic Science and Fisheries Abstracts, using combinations of the following keywords: marine fish, genetic*, population, structur* and gene flow. The survey was limited to strictly marine species, excluding anadromous and catadromous species. For each study, the fixation index of population substructuring (overall $F_{\mathrm{ST}}$ or $\Phi_{\mathrm{ST}}$ ) was obtained. In studies providing only pairwise $F_{\mathrm{ST}}$ between populations, we averaged the pairwise $F_{\mathrm{ST}}$ to obtain an overall $F_{\text {ST }}$.

The task of accounting for all variables potentially affecting marine fish population genetic structure is challenging, given the diversity in life-history, demography, behaviour and evolutionary history of marine fish. Yet, to investigate the effect of sex change on population genetic parameters, it was necessary to attempt a correction for as many potentially confounding factors as possible. Thus, two groups of variables were recorded (Table 1): nine 'methodological variables' related to sampling and analytical procedures and 10 'ecological variables'. Methodological variables included the mean number of fish sampled per site, the sampling area perimeter (recorded using Path Tool in Google Earth available at http://earth. google.com), the latitudinal and longitudinal sampling range which allowed us to assess the percentage of species distribution range effectively sampled, the presence of an environmental barrier between sampled populations, which is presumed to limit gene flow (the barrier was either defined by the authors of the study or was generally accepted from previous work, such as the Mediterranean Sea-Atlantic transition), and finally the type of marker used (microsatellites, mtDNA and allozymes). Ecological variables included the number of FAO areas ('Food and Agriculture Organization of the UN': http://www.fao.org) where each species is found, the maximum depth, the type of egg 
Table 1 Correlation of continuous (Pearson) and binary variables (Spearman) with the first three PCO axes.

\begin{tabular}{|c|c|c|c|c|c|c|}
\hline & \multicolumn{3}{|l|}{ mtDNA } & \multicolumn{3}{|l|}{ Nuclear DNA } \\
\hline & PC01 (29\%) & PC02 (22\%) & PC03 (12\%) & PC01 (25\%) & PC02 (21\%) & PC03 (15\%) \\
\hline \multicolumn{7}{|l|}{ Continuous variables } \\
\hline Study latitudinal range (degrees) & $-0.24^{\star}$ & $-0.67^{\star}$ & -0.10 & $0.28^{*}$ & $-0.35^{\star}$ & 0.03 \\
\hline Study longitudinal range (degrees) & $-0.42^{*}$ & $-0.50^{\star}$ & -0.14 & $0.37^{\star}$ & $-0.48^{\star}$ & $0.31^{*}$ \\
\hline stLat/spLat $(\%)$ & $0.23^{*}$ & $-0.75^{\star}$ & 0.05 & -0.18 & $-0.50^{\star}$ & 0.03 \\
\hline stLon/spLon (\%) & 0.19 & $-0.74^{\star}$ & $0.37^{*}$ & $-0.26^{\star}$ & $-0.67^{\star}$ & 0.16 \\
\hline Study surface/species distribution (\%) & $0.27^{\star}$ & $-0.80^{*}$ & 0.12 & $-0.33^{*}$ & $-0.59^{\star}$ & 0.04 \\
\hline Perimeter of the sampled area $(\mathrm{km})$ & $-0.44^{*}$ & $-0.56^{\star}$ & -0.09 & $0.29^{*}$ & $-0.38^{\star}$ & 0.04 \\
\hline Number of sites & $0.32^{*}$ & $-0.47^{\star}$ & $0.33^{*}$ & $-0.28^{*}$ & -0.02 & $0.22^{*}$ \\
\hline Total number of individual sampled & 0.10 & -0.02 & $0.45^{\star}$ & $-0.23^{*}$ & $0.25^{\star}$ & $0.39^{*}$ \\
\hline Mean number of individual per site & -0.17 & 0.12 & 0.22 & -0.08 & $0.22^{*}$ & 0.27 \\
\hline Maximum size $(\mathrm{cm})$ & $-0.58^{\star}$ & 0.07 & $0.38^{*}$ & $0.64^{\star}$ & -0.03 & 0.04 \\
\hline Maximum age (years) & 0.06 & 0.14 & $0.38^{\star}$ & $-0.21^{*}$ & $-0.32^{\star}$ & 0.14 \\
\hline Growth rate $(K)$ & 0.02 & $0.27^{\star}$ & $-0.45^{\star}$ & $-0.28^{*}$ & $0.36^{*}$ & 0.14 \\
\hline Species latitudinal range (degrees) & $-0.75^{\star}$ & 0.15 & -0.14 & $0.77^{\star}$ & 0.08 & -0.12 \\
\hline Species longitudinal range (degrees) & $-0.61^{*}$ & 0.20 & $-0.66^{\star}$ & $0.49^{*}$ & 0.16 & $0.37^{\star}$ \\
\hline Depth $(m)$ & -0.26 & 0.15 & $0.41^{*}$ & 0.13 & 0.17 & 0.04 \\
\hline Number of FAO & $-0.82^{\star}$ & 0.07 & $-0.27^{\star}$ & $0.68^{\star}$ & 0.06 & 0.16 \\
\hline \multicolumn{7}{|l|}{ Binary variables } \\
\hline Presence of geographical barrier & $-0.34^{*}$ & $-0.77^{\star}$ & -0.24 & $0.38^{\star}$ & $-0.65^{\star}$ & $0.54^{\star}$ \\
\hline Type of eggs (pelagic or not) & $-0.65^{\star}$ & 0.07 & $0.31^{*}$ & $0.80^{\star}$ & -0.17 & $-0.38^{*}$ \\
\hline Type of habitat (pelagic or not) & $-0.78^{\star}$ & -0.03 & $0.32^{*}$ & $0.26^{*}$ & $0.57^{\star}$ & $0.63^{*}$ \\
\hline
\end{tabular}

Values are given for mitochondrial and nuclear DNA. Percentage of variance explained by each axis is indicated in brackets ( ${ }^{*}$ uncorrected $P<0.05$, values in bold are significant after sequential Bonferroni correction).

(pelagic or demersal) and the type of adult habitat (pelagic, benthopelagic and bathypelagic species were grouped into the category 'pelagic' while demersal, bathydemersal and reef-associated species were grouped into 'demersal'), latitudinal and longitudinal range, maximum size and age, and the growth rate parameter $(K)$ of the Von Bertalanffy (1938) growth function (details in Table 1). Data on larval duration could only be retrieved for about $50 \%$ of species.

\section{Data analysis}

Most $F_{\mathrm{ST}}$-values were measured following the Weir and Cockerham (1984), which corrects for sample size and the number of populations used. When the method did not use any sample size correction, we subtracted $1 / 2 S$ from the $F_{\mathrm{ST}}$-estimates, where $S$ is the harmonic mean sample size (Wright 1978). To adjust $F_{\mathrm{ST}}$ for the higher genetic diversity of microsatellites, we used Hedrick's method (formula 4b in Hedrick 2005), which computes the adjusted $F_{\text {ST }} \quad\left(F_{\text {STadj }}\right)$ from the expected heterozygosity $\left(H_{\mathrm{E}}\right.$ : the expected frequency of heterozygotes under the Hardy-Weinberg equilibrium assumption, averaged across populations) and the number of subpopulations $(k)$ such that:

$$
F_{\text {STadj }}=\frac{F_{\mathrm{ST}}\left(k-1+H_{\mathrm{E}}\right)}{(k-1)\left(1-H_{\mathrm{E}}\right)} .
$$

Although historical isolation events affect $F_{\text {ST-estimates in non-equilibrium populations }}$ (Ryman and Leimar 2008), the effect tends to disappear in populations at migration/drift equilibrium, and in absence of detailed information on the dominant causes of substructuring on each one of the cases examined, Hedrick's adjustment is still an advisable practice (Jost 2008).

As both continuous and binary variables were employed in our study, we explored our dataset using a principal coordinates analysis (PCO) using two R (Free Software Foundation Inc, Boston, MA, USA) packages: 'Cluster' and 'Labdsv' ('R' version 2.6.1). Similarity matrices were computed using the Gower index, which standardizes binary and continuous variables on the same range from 0 to 1 (Gower 1971). Ordination techniques such as PCO 
can reduce the variance contained in a complex multivariate data set into a few synthetic 'axes' (eigenvectors). Subsequently, we assessed the association of each of the original variables and the principal coordinates extracted using the Pearson correlation, for continuous variables, and the Mann-Whitney test for binary ones. We adjusted $P$-value thresholds using a sequential Bonferroni correction for multiple testing, applying the correction separately for the 16 continuous variables and the three binary ones. We could then employ the principal coordinates extracted as multivariate measures of 'methodological and ecological biases' and assess their association with $F_{\mathrm{ST}} /\left(1-F_{\mathrm{ST}}\right)$ using a linear regression approach. $F_{\mathrm{ST}} /\left(1-F_{\mathrm{ST}}\right)$ is routinely used for regression against geographical distance, and this transformation has been shown to be more suitable than $F_{\mathrm{ST}}$ for linear regression (Rousset 1997). As information on larval duration was only available for half of the species examined, we could not use this variable in our main multivariate analysis, but details on analyses performed on a reduced data set including larval duration information are reported in the Supporting Information. Given the different nature and properties of nuclear and mitochondrial markers, we conducted all analyses independently for the two groups of datasets.

When $F_{\mathrm{ST}^{-}}$-values were shown to be correlated with either PCO1, PCO2 or PCO3 (seen as multivariate combinations of mainly dispersal- and sampling-related variables, see Results), we used these principal coordinates in a general linear model to control for their effects and then tested for differences between groups. For instance, in cases where the linear regression of $F_{\mathrm{ST}} /\left(1-F_{\mathrm{ST}}\right)$ against PCO1 was significant, residuals of this regression were used to test the differences among reproductive modes. Two designs were explored: a two-group comparison (gonochorists vs. hermaphrodites) and a three-group comparison of gonochorists, protandrous and protogynous.

\section{Results}

We recorded $157 F_{\mathrm{ST}^{-}}$-datapoints from 99 species of marine fish, of which 19 were protogynous and only seven protandrous. Five families of protogynous species (Serranidae, Labridae, Scaridae, Pomacentridae and Lethrinidae) and three families of protandrous (Sparidae, Pomacentridae and Latidae) were represented. The $F_{\mathrm{ST}}$-distribution was skewed, with an average of $0.131(\mathrm{SD}=0.201)$ and a median of 0.036 . The average expected heterozygosity measured was 0.12 for allozymes and 0.78 for microsatellites. Hedrick's adjustment of $F_{\mathrm{ST}}$ to account for differential polymorphism of markers

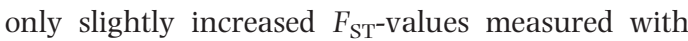
allozymes, whereas adjusted $F_{\mathrm{ST}}$-values for microsatellites were about five times higher than nonadjusted ones. After Hedrick's adjustments, mean $F_{\mathrm{ST}} /\left(1-F_{\mathrm{ST}}\right)$ values were 0.115 for nuclear DNA data and 0.178 for mtDNA, which proved not to be significantly different (Kruskal-Wallis $\mathrm{H}_{2 ; 157}=$ 5.99, $P=0.891$ ); however, the highest values were measured in studies using mitochondrial DNA.

\section{Effect of sampling effort and species dispersal ability}

The first axis (PCO1) accounted for 29\% of the total variance for mitochondrial DNA studies and $25 \%$ for the nuclear DNA dataset; PCO2 accounted for $22 \%$ and $21 \%$ of the variation for mtDNA and nuclear data respectively, while $\mathrm{PCO} 3$ explained $12 \%$ and $15 \%$ of the total variance for respectively mitochondrial and nuclear data sets (Table 1, Fig. 1). With mtDNA, ecological variables related to species distribution range, habitat use and dispersal capabilities (latitudinal and longitudinal distribution range, number of FAO areas where the species is found, the maximum size of species, pelagic eggs and pelagic habitat) were negatively correlated with PCO1 (Table 1). Methodological variables related to sampling (study latitudinal and longitudinal ranges, the study perimeter, and the percentage of the species' range sampled), as well as the presence of geographical barrier, were negatively correlated with $\mathrm{PCO} 2$ (Table 1). PCO3 was negatively correlated with the $K$ growth parameter and positively associated with the total number of individuals analysed.

With nuclear DNA, PCO1 was positively correlated to the distribution and dispersal variables as well as the maximum species size, whilst PCO2 proved negatively correlated not only to variables related to the sampling area and to the presence of environmental barrier, but also to the pelagic habitat. PCO3 was only positively correlated to the number of individuals analysed (Table 1).

For both data sets, the first three axes explained more than $60 \%$ of the variance, with PCO1 consistently associated with the dispersal and distribution variables and $\mathrm{PCO} 2$ associated with the sampling area and the environmental barrier. Some of the 
(a)

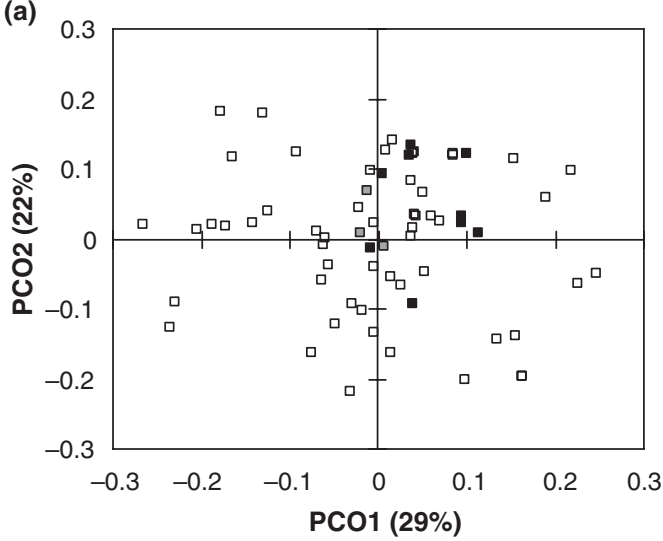

(b)

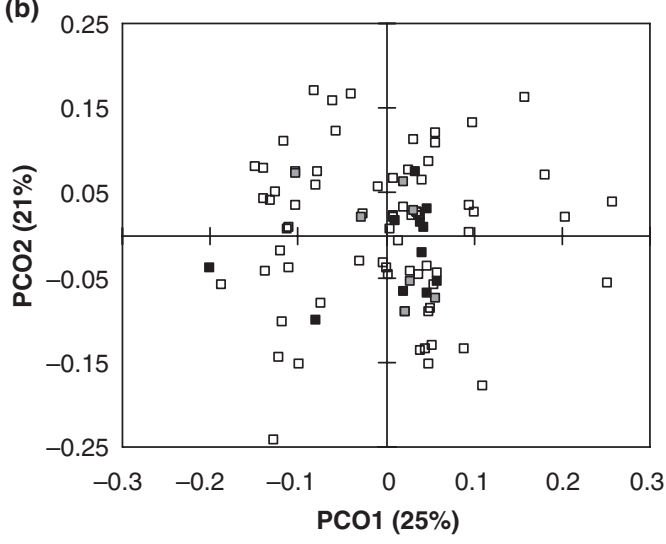

Figure 1 Scatter plot of data within the space identified by the first two Principal coordinates (PCO) extracted from a matrix including the 16 continuous and three binary variables of Table 1. Graphs are shown for (a) mitochondrial and (b) nuclear DNA. Data points are labelled according to the three types of reproductive modes: gonochorist (white), protandrous (grey) and protogynous (black).

variables were not fully independent (e.g. if a sampling area is very large, it is more likely to also comprise an environmental barrier), hence the occasional redundant association of some variables to more than one axis (Table 1); in such instances, we interpreted as the strongest correlation the one yielding the highest $R$ and the lowest $P$-values (Gotelli and Ellison 2004). Further PCO axes extracted were not associated to any variables not already strongly associated with PCO1, PCO2 or PCO3; due to their redundancy and the little variance explained (8-2\% for PCO3-10), they were not employed for further analyses.

Generally, irrespective of the marker, higher levels of $F_{\mathrm{ST}} /\left(1-F_{\mathrm{ST}}\right)$ were found with species with demersal eggs living in demersal habitat and in studies with a geographical barrier. Lower $F_{\mathrm{ST}} /\left(1-F_{\mathrm{ST}}\right)$ levels were associated with large pelagic species with pelagic eggs, high dispersal ability and large habitat use. However, this pattern was much stronger with mitochondrial DNA, where a significant correlation was observed between $F_{\mathrm{ST}} /\left(1-F_{\mathrm{ST}}\right)$ and the scores on both the first and the second axis (PCO1: $R=0.259, P<0.033$; PCO2: $R=-0.469, \quad P<0.0001$ ) (Fig. 2), while with nuclear DNA data, no significant relationships were observed with any PCO factor (Fig. 2). When the same analysis was conducted using a reduced dataset containing larval duration, the patterns observed were not substantially different (though a decrease in resolution power was noticeable); larval duration was not one of the variables correlated to $F_{\text {ST }}$-estimates (Table S3).

Testing the hypothesis: do sex-changing species show higher $\boldsymbol{F}_{\mathbf{S T}}$ ?

Figure 3 illustrates the adjusted $F_{\mathrm{ST}} /\left(1-F_{\mathrm{ST}}\right)$ values for gonochoristic, protandrous and protogynous species. Employing all the above correction procedures, and after removing the effects of PCO1 and PCO2 - in the case of mitochondrial DNA - and conducting a simple one-way ANOVA with nuclear DNA, no differences among reproductive modes were observed for either the two- or the three-group designs (Table 2).

\section{Discussion}

Highly biased sex ratios measured in populations of sequentially hermaphrodite fish are theoretically expected to lead to lower effective population size. In such a scenario, the effective population of males and females are measured separately, such that the overall $N_{\mathrm{e}}$ is equal to $4\left(N_{\mathrm{ef}} N_{\mathrm{em}}\right) /\left(N_{\mathrm{ef}}+N_{\mathrm{em}}\right)$, with $N_{\text {em }}$ and $N_{\text {ef }}$ being the effective population size of males and females respectively. In this model, any sex-ratio departure from unity leads to lower effective size (Crow and Kimura 1970). Consequently, we predicted that sequentially hermaphrodite fish with biased sex ratio and theoretically lower effective population size experience higher genetic drift, leading to higher genetic structuring. Such a hypothesis has never been tested, although it can potentially have big consequences on the management of several commercially important species. Cotton and Wedekind (2009) have also briefly emphasized the importance of sex ratio 

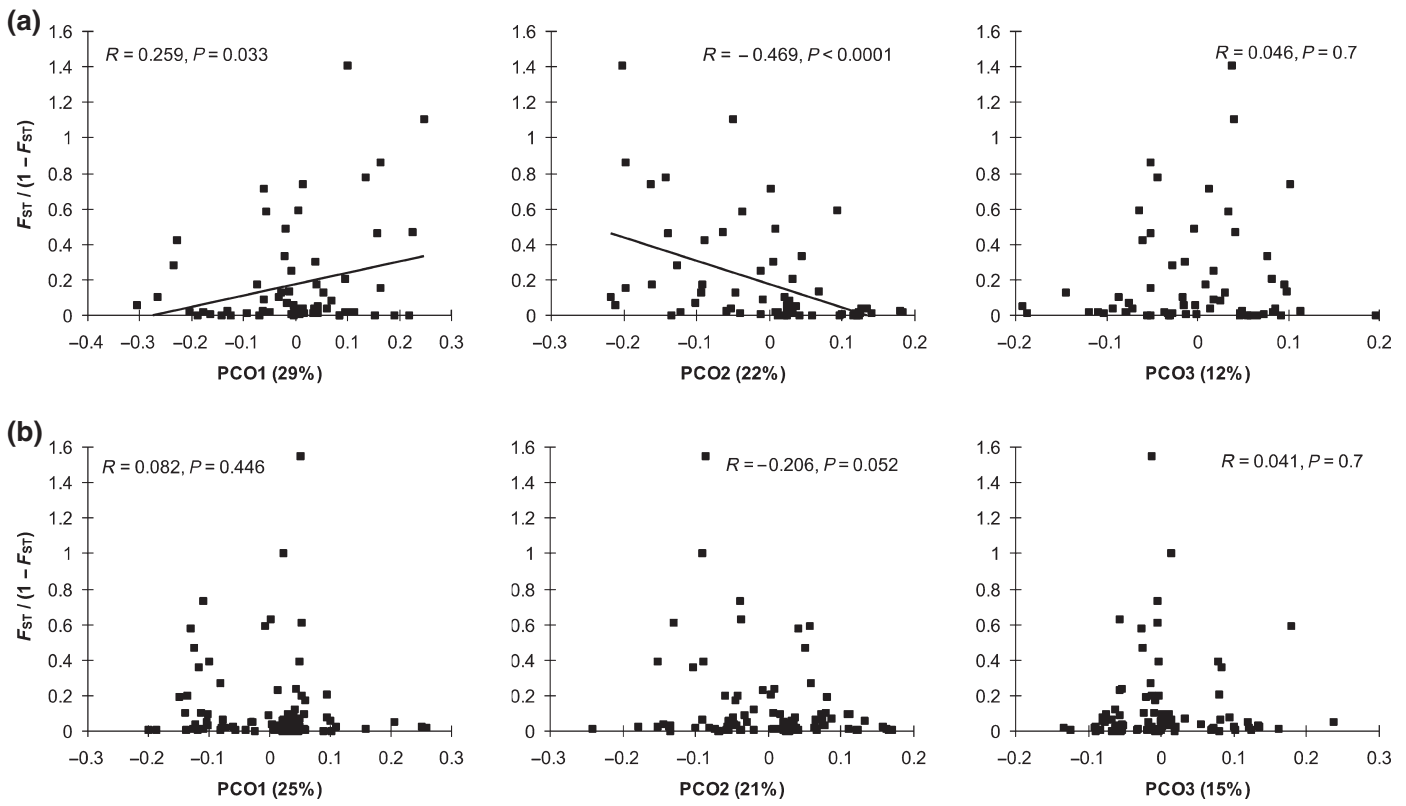

Figure 2 Relationships between $F_{\mathrm{ST}} /\left(1-F_{\mathrm{ST}}\right)$ and the three principal coordinates (PCO1, PCO2 and PCO3) for (a) mitochondrial and (b) nuclear DNA. $R$ is the correlation coefficient. Trend lines are shown for significant correlations.

on $N_{\mathrm{e}}$ in fish, but focusing on the changes caused by environmentally induced feminization/masculinization. In this study, we attempted to assess the potential effect of sex change on the population structure $\left(F_{\mathrm{ST}}\right)$ of marine fish using published data from many studies. After adjusting for the effect of dispersal ability and analysing mtDNA and nuclear DNA separately, it appeared that the remaining variation of population structure was not explained by the incidence of sex change.

It should be stressed again that the number of ecological, historical, analytical factors - and their interplay - that can affect the degree of genetic structuring in marine fish populations is considerable (Selkoe et al. 2008), especially when relying upon published data gathered across diverse species over a period of 20 years. Although we accounted for these covariates in our analyses to the extent possible, they undoubtedly reduced the power to test for effects of sex ratio. Furthermore, the number of studies on sex-changing fish available in the literature was limited, which obviously decreases the power of our comparison. Although a larger number of studies on hermaphroditic species would certainly be desirable, we suspect that substantially different results are unlikely. Indeed, several sexchanging species present low levels of population structure, such as the California Sheephead
(Semicossyphus pulcher, Labridae) and the Rock wrasse (Halichoeres semicinctus, Labridae) (Waples 1987; Bernardi et al. 2003) or the White seabream (Diplodus sargus, Sparidae) (Bargelloni et al. 2005) and the Carolines parrotfish (Calotomus carolinus, Scaridae) (Lessios and Robertson 2006). On the other hand, several gonochoristic species present very strong population structure, such as the Silver gemfish (Rexea solandri, Gempylidae) (Ward and Elliott 2001) and the Long-spine porcupine fish (Diodon holocanthus, Diodontidae) (Lessios and Robertson 2006). Based on the above caveats, the apparent lack of impact of sex change should be interpreted with some caution, though, such factors can stimulate new working hypotheses and the development of more focused experimental investigations.

Factors associated with the dispersal ability of species accounted for a large part of variation in population genetic structure. The swamping effect of high gene flow resulting from the dispersal of highly migratory pelagic species is indeed able to prevent strong genetic structuring in many species of scombrids, billfishes, carangids, clupaeids, etc.; however, interestingly, we found a strong signal only with mtDNA (Fig. 2). On the one hand, this could support the traditional view that the lower effective size of mtDNA (due to haploidy and 
(a)

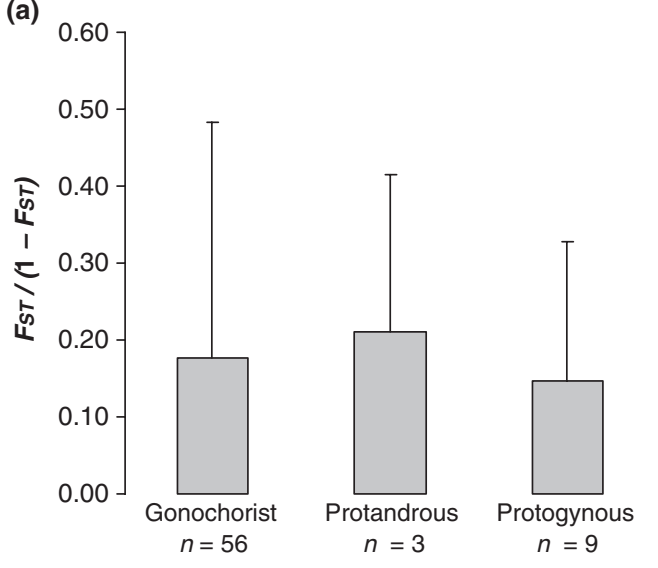

(b)
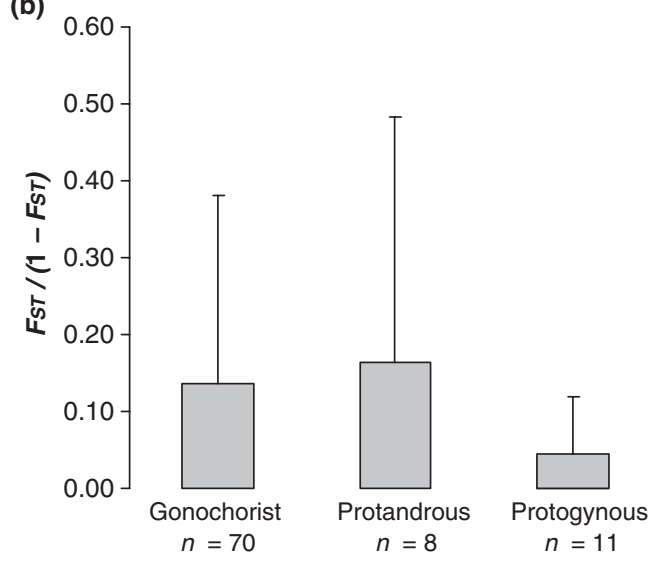

Figure 3 Average $F_{\mathrm{ST}} /\left(1-F_{\mathrm{ST}}\right)$ ( \pm standard deviation) for three different reproductive modes (gonochorist, protogynous, protandrous), obtained with both (a) mitochondrial and (b) nuclear DNA.

matrilinear inheritance) would result in greater genetic structuring than at nuclear markers (Avise 2004). On the other hand, a variety of other factors can affect the relative differentiation of mtDNA and nuclear markers, including different mutation rates, the higher degree of homoplasy at microsatellites, which are constrained to allelic size ranges, and the confounding factor that $F_{\mathrm{ST}}$ is a function of the level of genetic variability (Ryman and Leimar 2008). In this light, the effect of dispersal-related variables might have shaped the genetic structure of marine fish mainly over the longer time scales (past climatic and geological events) on which information can be gathered through mtDNA variation (e.g. Buonaccorsi et al. 2001; Lecomte et al. 2004; Durand et al. 2005; Gonzalez and Zardoya 2007). In contrast, microsatellites provide insights into
Table 2 Analysis of variance testing for differences in $F_{\mathrm{ST}} /\left(\mathrm{l}-F_{\mathrm{ST}}\right)$ among reproductive modes: (a) gonochorists vs. protandrous vs. protogynous (mitochondrial DNA), (b) gonochorists vs protandrous vs. protogynous (nuclear DNA), (c) gonochorists vs. sequential hermaphrodite (mtDNA), (d) gonochorists vs. sequential hermaphrodites (nuclear DNA).

\begin{tabular}{|c|c|c|c|c|}
\hline Source & $d f$ & SS & $F$ & $P$-value \\
\hline \multicolumn{5}{|l|}{ (a) } \\
\hline PCO1 & 1 & 0.37 & 5.73 & 0.020 \\
\hline $\mathrm{PCO} 2$ & 1 & 1.22 & 19.09 & $<0.0001$ \\
\hline Reproduction & 2 & 0.02 & 0.12 & 0.883 \\
\hline Residuals & 63 & 4.03 & & \\
\hline Total & 67 & 5.68 & & \\
\hline \multicolumn{5}{|l|}{ (b) } \\
\hline Reproduction & 2 & 0.09 & 0.75 & 0.474 \\
\hline Residuals & 86 & 5.06 & & \\
\hline Total & 88 & 5.15 & & \\
\hline \multicolumn{5}{|l|}{ (c) } \\
\hline PC01 & 1 & 0.36 & 5.65 & 0.020 \\
\hline PC02 & 1 & 1.24 & 19.57 & $<0.0001$ \\
\hline Reproduction & 1 & 0.00 & 0.08 & 0.780 \\
\hline Residuals & 64 & 4.04 & & \\
\hline Total & 67 & 5.68 & & \\
\hline \multicolumn{5}{|l|}{ (d) } \\
\hline Reproduction & 1 & 0.02 & 0.42 & 0.519 \\
\hline Residuals & 87 & 5.12 & & \\
\hline Total & 88 & 5.15 & & \\
\hline
\end{tabular}

With mitochondria DNA, the principal components PCO1 and $\mathrm{PCO} 2$ were included in the analysis as covariates.

more recent/contemporary processes, and several recent studies (Knutsen et al. 2004; Hemmer-Hansen et al. 2007b; Galarza et al. 2009) have shown that patterns of present-day population structure in marine fish may be strongly linked to oceanographical features, which were among the factors we could not incorporate in our study.

We expected that sequential hermaphroditism would be a major factor in determining biased sex ratio, but a sex ratio estimate at any given point in time may be an over-simplistic and misleading approximation in species that can change sex under a range of environmental conditions. Moreover, sex ratio might also be biased in gonochoristic species (Morgan and Trippel 1996). A number of examples of biased sex ratio in gonochoristic marine fish have been recorded for several species like the sand goby (Pomatoschistus minutus, Gobiidae) (Kvarnemo et al. 1995), with several factors possibly affecting the operational sex ratio (e.g. age and size at maturity, the mortality rate or the migration patterns). 
Dramatic changes in the sex ratio, in both gonochorist and hermaphrodite species, may occur spatially and temporally in allopatric populations and in different seasons (Garratt 1985; Demartini et al. 2000). Furthermore, it has been suggested that while biased sex ratio is among the factors affecting effective population size and population structure, it might not be the most important one. High variance in individual reproductive success is known to be responsible for the discrepancy between census size and effective size in species with high fecundity and high juvenile mortality (Hauser and Carvalho 2008). In contrast to species that release eggs in the water column, such as the majority of commercial species, several other fishes display parental care that may improve offspring fitness and reduce variance in individual reproductive success. Other factors should ideally also be considered, such as the type of overlapping generations, the generation time and longevity, which, in the case of isolated populations, may affect evolutionary rates (Hill 1979; Shulman 1998; Turner et al. 2002). In addition, historical factors inducing census size fluctuations are also expected to affect long-term $N_{\mathrm{e}}$ (Hauser et al. 2002; Kalinowski and Waples 2002; Turner et al. 2002): populations sampled may have undergone several size reductions and expansions with significant fluctuations of their genetic diversity and effective size. Finally, breeding competition, the diversity of reproductive behaviour and mating systems even in gonochoristic species may also potentially affect the effective size of populations, but these have so far received relatively little attention (Rowe et al. 2008) and it was not feasible to include them in our model.

In summary, despite the strong theoretical background predicting higher potential for population genetic structure in hermaphrodite species, we could not reject the null hypothesis of no difference in population structuring among reproductive modes. As discussed above, this is likely to depend on a range of biological factors not accounted for, such as: reproductive potential, natural $N_{\mathrm{e}} / N$ ratio, generation time, etc. - which cannot be assumed to be equal across gonochoristic and sequentially hermaphroditic species.

One contribution of this study is that of underpinning the paradigm that the dispersal abilities and the existence of environmental barriers account for an important proportion of the variance in the genetic structuring of marine fish populations. Our findings echo previous multispecies investigations and reviews (see Ward et al. 1994; Doherty et al. 1995; Bohonak 1999); yet, the more or less subtle inconsistencies between different classes of genetic markers, the still largely incomplete knowledge on life-histories, and the paucity of empirical integrations of physical oceanographical models with biological and genetic data (Werner et al. 2007), all indicate that more effort is required to more fully unravel the processes driving marine population connectivity. An immediate next step towards a more controlled assessment of the population genetic consequences of sequential hermaphroditism, could be obtained by conducting empirical studies on closely related species of fish - some gonochoristic, some sequentially hermaphroditic with carefully matched life-history traits, and demographics, and conducting a carefully consistent sampling and analytical protocol, employing both nuclear and mitochondrial markers.

In conclusion, we hypothesized that uneven sex ratio observed in hermaphroditic species could depress $N_{\mathrm{e}}$ and consequently increase population structure; yet, we found no support for this hypothesis by examining hundreds of published studies on marine fish. However, we argue that the very nature of sequential hermaphroditism introduces a degree of complexity in population genetics modelling that has so far received very little attention. Sex change has long been seen as an evolutionary adaptation to increase lifetime reproductive success (Warner 1975, 1988b), yet, because in hermaphrodite species many individuals of the first sex exhibit a relatively low reproductive success (few mating opportunities with high competition), compared with the few individuals of the second sex, such features may also increase the variance in individual reproductive success, with consequences on the effective population size that are still poorly understood. It should be noted that $N_{\mathrm{e}}$ is affected not only by the skew of sex ratios measured at any given time, but rather by the lifetime effective sex ratio. Although sequentially hermaphroditism should potentially reduce the $N_{\mathrm{e}} / \mathrm{N}$ ratio, this has never been explored/modelled in depth. Furthermore, the fact that a proportion of a sex-changing population can reproduce at different times, both as a male as well as a female, will affect the relative signatures detectable with maternally and biparentally inherited molecular genetic markers, because mtDNA has the potential to be transmitted by all individuals in the population. Future empirical and modelling studies on 
sex-changing fish may either confirm or reappraise the significance of sequential hermaphroditism for the population structuring of marine species, but will for certain provide new valuable insights towards the understanding of this intriguing lifehistory strategy.

\section{Acknowledgements}

This study is part of JC's doctoral studies, which form part of a grant supported by the Research Frontiers Programme of Science Foundation Ireland (SFI). We thank Tasman Crowe and Michele Scardi for support in statistical analyses and Nathaniel Jue for help in data collection. We also thank Dave Weetman, Myriam Callier, Bruce Mann, Gary Carvalho and three anonymous reviewers for the insightful and constructive criticism that helped us improve the study.

\section{References}

Allsop, D.J. and West, S.A. (2003) Changing sex at the same relative body size - Similar forces may select for gender switching across taxa in all animals with this facility. Nature 425, 783-784.

Allsop, D.J. and West, S.A. (2004) Sex-ratio evolution in sex changing animals. Evolution 58, 1019-1027.

Alonzo, S.H. and Mangel, M. (2004) The effects of sizeselective fisheries on the stock dynamics of and sperm limitation in sex-changing fish. Fishery Bulletin 102, 113.

Avise, J.C. (2004) Molecular Markers, Natural History, and Evolution. Sinauer Associates, Sunderland, MA.

Bargelloni, L., Alarcon, J.A., Alvarez, M.C., Penzo, E., Magoulas, A., Reis, C. and Patarnello, T. (2003) Discord in the family Sparidae (Teleostei): divergent phylogeographical patterns across the Atlantic-Mediterranean divide. Journal of Evolutionary Biology 16, 1149-1158.

Bargelloni, L., Alarcon, J.A., Alvarez, M.C., Penzo, E., Magoulas, A., Palma, J. and Patarnello, T. (2005) The Atlantic-Mediterranean transition: discordant genetic patterns in two seabream species, Diplodus puntazzo (Cetti) and Diplodus sargus (L.). Molecular Phylogenetics and Evolution 36, 523-535.

Bay, L.K., Crozier, R.H. and Caley, M.J. (2006) The relationship between population genetic structure and pelagic larval duration in coral reef fishes on the Great Barrier Reef. Marine Biology 149, 1247-1256.

Beentjes, M.P. and Carbines, G.D. (2005) Population structure and relative abundance of blue cod (Parapercis colias) off Banks Peninsula and in Dusky Sound, New Zealand. New Zealand Journal of Marine and Freshwater Research 39, 77-90.
Beheregaray, L.B. and Sunnucks, P. (2001) Fine-scale genetic structure, estuarine colonization and incipient speciation in the marine silverside fish Odontesthes argentinensis. Molecular Ecology 10, 2849-2866.

Bernardi, G. (2000) Barriers to gene flow in Embiotoca jacksoni, a marine fish lacking a pelagic larval stage. Evolution 54, 226-237.

Bernardi, G. and Vagelli, A. (2004) Population structure in Banggai cardinalfish, Pterapogon kauderni, a coral reef species lacking a pelagic larval phase. Marine Biology 145, 803-810.

Bernardi, G., Findley, L. and Rocha-Olivares, A. (2003) Vicariance and dispersal across Baja California in disjunct marine fish populations. Evolution 57, 15991609.

Blandon, I.R., Ward, R., King, T.L., Karel, W.J. and Monaghan, J.P., Jr (2001) Preliminary genetic population structure of southern flounder, Paralichthys lethostigma, along the Atlantic Coast and Gulf of Mexico. Fishery Bulletin 99, 671-678.

Bohonak, A.J. (1999) Dispersal, gene flow, and population structure. The Quarterly Review of Biology 74, 21-45.

Bonhomme, F., Naciri, M., Bahri-Sfar, L. and Lemaire, C. (2002) Comparative analysis of genetic structure of two closely related sympatric marine fish species Dicentrarchus labrax and Dicentrarchus punctatus. Comptes Rendus Biologies 325, 213-220.

Borsa, P., Blanquer, A. and Berrebi, P. (1997) Genetic structure of the flounders Platichthys flesus and P. stellatus at different geographic scales. Marine Biology 129, 233-246.

Bridle, J.R. and Vines, T.H. (2007) Limits to evolution at range margins: when and why does adaptation fail? Trends in Ecology \& Evolution 22, 140-147.

Brutto, S.L., Arculeo, M. and Parrinello, N. (2004) Congruence in genetic markers used to describe Mediterranean and Atlantic populations of European hake (Merluccius merluccius L. 1758). Journal of Applied Ichthyology 20, 81-86.

Buonaccorsi, V.P., Mcdowell, J.R. and Graves, J.E. (2001) Reconciling patterns of inter-ocean molecular variance from four classes of molecular markers in blue marlin Makaira nigricans. Molecular Ecology 10, 1179-1196.

Byers, J.E. and Pringle, J.M. (2006) Going against the flow: retention, range limits and invasions in advective environments. Marine Ecology Progress Series 313, 2741.

Chenoweth, S.F., Hughes, J.M., Keenan, C.P. and Lavery, S. (1998) When oceans meet: a teleost shows secondary intergradation at an Indian-Pacific interface. Proceedings of the Royal Society of London Series B - Biological Sciences 265, 415-420.

Cimmaruta, R., Bondanelli, P. and Nascetti, G. (2005) Genetic structure and environmental heterogeneity in the European hake (Merluccius merluccius). Molecular Ecology 14, 2577-2591. 
Cotton, S. and Wedekind, C. (2009) Population consequences of environmental sex reversal. Conservation Biology 23, 196-206.

Crow, J.F. and Kimura, M. (1970) An Introduction to Population Genetics Theory. Harper \& Row, New York, London.

Demartini, E.E., Uchiyama, J.H. and Williams, H.A. (2000) Sexual maturity, sex ratio, and size composition of swordfish, Xiphias gladius, caught by the Hawaii-based pelagic longline fishery. Fishery Bulletin 98, 489-506.

Devlin, R.H. and Nagahama, Y. (2002) Sex determination and sex differentiation in fish: an overview of genetic, physiological, and environmental influences. Aquaculture 208, 191-364.

Doherty, P.J., Planes, S. and Mather, P. (1995) Gene flow and larval duration in 7 species of fish from the GreatBarrier-Reef. Ecology 76, 2373-2391.

Durand, J.D., Collet, A., Chow, S., Guinand, B. and Borsa, P. (2005) Nuclear and mitochondrial DNA markers indicate unidirectional gene flow of Indo-Pacific to Atlantic bigeye tuna Thunnus obesus populations, and their admixture off southern Africa. Marine Biology 147, 313-322.

Frisch, A. (2004) Sex-change and gonadal steroids in sequentially-hermaphroditic teleost fish. Reviews in Fish Biology and Fisheries 14, 481-499.

Galarza, J.A., Carreras-Carbonell, J., MacPherson, E., Pascual, M., Roques, S., Turner, G.F. and Rico, C. (2009) The influence of oceanographic fronts and earlylife-history traits on connectivity among littoral fish species. Proceedings of the National Academy of Sciences of the United States of America 106, 1473-1478.

Garratt, P.A. (1985) The offshore linefishery of Natal: I: exploited population structure of the Sparids Chrysoblephus puniceus and Cheimerius nufar. Oceanographic Research Institute, Investigational Report 62, 1-18.

Gold, J.R. and Richardson, L.R. (1998) Mitochondrial DNA diversification and population structure in fishes from the Gulf of Mexico and western Atlantic. Journal of Heredity 89, 404-414.

Gonzalez, E.G. and Zardoya, R. (2007) Relative role of lifehistory traits and historical factors in shaping genetic population structure of sardines Sardina pilchardus. BMC Evolutionary Biology 7, 197-209.

Gotelli, J.G. and Ellison, A.M. (2004) A Primer of Ecological Statistics. Sinauer Associates, Sunderland, MA.

Gower, J.C. (1971) A general coefficient of similarity and some of its properties. Biometrics 27, 623-637.

Grant, W.S. and Bowen, B.W. (1998) Shallow population histories in deep evolutionary lineages of marine fishes: Insights from sardines and anchovies and lessons for conservation. Journal of Heredity 89, 415426.

Gysels, E.S., Hellemans, B., Pampoulie, C. and Volckaert, F.A.M. (2004a) Phylogeography of the common goby, Pomatoschistus microps, with particular emphasis on the colonization of the Mediterranean and the North Sea Molecular Ecology 13, 403-417.

Gysels, E.S., Hellemans, B., Patarnello, T. and Volckaert, F.A.M. (2004b) Current and historic gene flow of the sand goby Pomatoschistus minutus on the European Continental Shelf and in the Mediterranean Sea. Biological Journal of the Linnean Society 83, 561-576.

Hartl, D.L. and Clark, A.G. (1997) Principles of Population Genetics. Sinauer Associates, Sunderland, MA.

Hauser, L. and Carvalho, G.R. (2008) Paradigm shifts in marine fisheries genetics: ugly hypotheses slain by beautiful facts. Fish and Fisheries 9, 333-362.

Hauser, L., Adcock, G.J., Smith, P.J., Ramirez, J.H.B. and Carvalho, G.R. (2002) Loss of microsatellite diversity and low effective population size in an overexploited population of New Zealand snapper (Pagrus auratus). Proceedings of the National Academy of Sciences of the United States of America 99, 11742-11747.

Hawkins, J.P. and Roberts, C.M. (2004) Effects of fishing on sex-changing Caribbean parrotfishes. Biological Conservation 115, 213-226.

Hedgecock, D. (1994) Temporal and spatial geneticstructure of marine animal populations in the California Current. California Cooperative Oceanic Fisheries Investigations Reports 35, 73-81.

Hedrick, P.W. (2005) A standardized genetic differentiation measure. Evolution 59, 1633-1638.

Hemmer-Hansen, J., Nielsen, E.E., Frydenberg, J. and Loeschcke, V. (2007a) Adaptive divergence in a high gene flow environment: Hsc70 variation in the European flounder (Platichthys flesus L.). Heredity 99, 592600.

Hemmer-Hansen, J., Nielsen, E.E., Groenkjaer, P. and Loeschcke, V. (2007b) Evolutionary mechanisms shaping the genetic population structure of marine fishes; lessons from the European flounder Platichthys flesus L. Molecular Ecology 16, 3104-3118.

Hickerson, M.J. and Ross, J.R. (2001) Post-glacial population history and genetic structure of the northern clingfish (Gobiesox maeandricus), revealed from mtDNA analysis. Marine Biology 138, 407-419.

Hill, W.G. (1979) Note on effective population-size with overlapping generations. Genetics 92, 317-322.

Hoarau, G., Boon, E., Jongma, D.N. et al. (2005) Low effective population size and evidence for inbreeding in an overexploited flatfish, plaice (Pleuronectes platessa L.). Proceedings of the Royal Society B - Biological Sciences 272, 497-503.

Hutchinson, W.F., Van Oosterhout, C., Rogers, S.I. and Carvalho, G.R. (2003) Temporal analysis of archived samples indicates marked genetic changes in declining North Sea cod (Gadus morhua). Proceedings of the Royal Society of London Series B - Biological Sciences 270 , 2125-2132.

Jost, L. (2008) $\mathrm{G}_{\mathrm{ST}}$ and its relatives do not measure differentiation. Molecular Ecology 17, 4015-4026. 
Kalinowski, S.T. and Waples, R.S. (2002) Relationship of effective to census size in fluctuating populations. Conservation Biology 16, 129-136.

Knutsen, H., Andre, C., Jorde, P.E., Skogen, M.D., Thuroczy, E. and Stenseth, N.C. (2004) Transport of North Sea cod larvae into the Skagerrak coastal populations. Proceedings of the Royal Society of London Series B Biological Sciences 271, 1337-1344.

Kuparinen, A. and Merila, J. (2007) Detecting and managing fisheries-induced evolution. Trends in Ecology \& Evolution 22, 652-659.

Kvarnemo, C., Forsgren, E. and Magnhagen, C. (1995) Effects of sex ratio on intra- and inter-sexual behaviour in sand gobies. Animal Behaviour 50, 1455-1461.

Lecomte, F., Grant, W.S., Dodson, J.J., Rodriguez-Sanchez, R. and Bowen, B.W. (2004) Living with uncertainty: genetic imprints of climate shifts in East Pacific anchovy (Engraulis mordax) and sardine (Sardinops sagax). Molecular Ecology 13, 2169-2182.

Lemaire, C., Allegrucci, G., Naciri, M., Bahri-Sfar, L., Kara, H. and Bonhomme, F. (2000) Do discrepancies between microsatellite and allozyme variation reveal differential selection between sea and lagoon in the sea bass (Dicentrarchus labrax)? Molecular Ecology 9, 457-467.

Lessios, H.A. and Robertson, D.R. (2006) Crossing the impassable: genetic connections in 20 reef fishes across the eastern Pacific barrier. Proceedings of the Royal Society B - Biological Sciences 273, 2201-2208.

Molloy, P.P., Goodwin, N.B., Cote, I.M., Gage, M.J.G. and Reynolds, J.D. (2007) Predicting the effects of exploitation on male-first sex-changing fish. Animal Conservation 10, 30-38.

Morgan, M.J. and Trippel, E.A. (1996) Skewed sex ratios in spawning shoals of Atlantic cod (Gadus morhua). ICES Journal of Marine Science 53, 820-826.

Munday, P.L., White, J.W. and Warner, R.R. (2006) A social basis for the development of primary males in a sex-changing fish. Proceedings of the Royal Society B Biological Sciences 273, 2845-2851.

Nagahama, Y. (2005) Molecular mechanisms of sex determination and gonadal sex differentiation in fish. Fish Physiology and Biochemistry 31, 105-109.

Nakadate, M., Vinas, J., Corriero, A., Clarke, S., Suzuki, N. and Chow, S. (2005) Genetic isolation between Atlantic and Mediterranean albacore populations inferred from mitochondrial and nuclear DNA markers. Journal of Fish Biology 66, 1545-1557.

Nee, S., Colegrave, N., West, S.A. and Grafen, A. (2005) The illusion of invariant quantities in life histories. Science 309, 1236-1239.

Nesbo, C.L., Rueness, E.K., Iversen, S.A., Skagen, D.W. and Jakobsen, K.S. (2000) Phylogeography and population history of Atlantic mackerel (Scomber scombrus L.): a genealogical approach reveals genetic structuring among the eastern Atlantic stocks. Proceedings of the
Royal Society of London Series B - Biological Sciences 267, 281-292.

Nielsen, E.E., Nielsen, P.H., Meldrup, D. and Hansen, M.M. (2004) Genetic population structure of turbot (Scophthalmus maximus L.) supports the presence of multiple hybrid zones for marine fishes in the transition zone between the Baltic Sea and the North Sea. Molecular Ecology 13, 585-595.

Nielsen, E.E., Hansen, M.M. and Meldrup, D. (2006) Evidence of microsatellite hitch-hiking selection in Atlantic cod (Gadus morhua L.): implications for inferring population structure in nonmodel organisms. Molecular Ecology 15, 3219-3229.

Palsboll, P.J., Berube, M. and Allendorf, F.W. (2007) Identification of management units using population genetic data. Trends in Ecology \& Evolution 22, 11-16.

Patarnello, T., Volckaert, F. and Castilho, R. (2007) Pillars of Hercules: is the Atlantic-Mediterranean transition a phylogeographical break? Molecular Ecology 16, 44264444.

Pindaro, D.J., Manuel, U.-A., Sofia, O.-G. and Durand, J.-D. (2006) Spatial and temporal mitochondrial DNA genetic homogeneity of dolphinfish populations (Coryphaena hippurus) in the eastern central Pacific. Fisheries Research (Amsterdam) 80, 333-338.

Planes, S. and Doherty, P.J. (1997) Genetic relationships of the colour morphs of Acanthochronis polyacanthus (Pomacentridae) on the northern Great Barrier Reef. Marine Biology 130, 109-117.

Planes, S. and Romans, P. (2004) Evidence of genetic selection for growth in new recruits of a marine fish. Molecular Ecology 13, 2049-2060.

Price, D.J. (1984) Genetics of sex determination in fishes a brief review. In: Fish Reproduction: Strategies and Tactics (eds G.W. Potts and R.J. Wootton). Academic Press, London, pp. 77-89.

Pringle, J.M. and Wares, J.P. (2007) Going against the flow: maintenance of alongshore variation in allele frequency in a coastal ocean. Marine Ecology Progress Series 335, 69-84.

Riginos, C. and Nachman, M.W. (2001) Population subdivision in marine environments: the contributions of biogeography, geographical distance and discontinuous habitat to genetic differentiation in a blennioid fish, Axoclinus nigricaudus. Molecular Ecology 10, 1439-1453.

Riginos, C. and Victor, B.C. (2001) Larval spatial distributions and other early life-history characteristics predict genetic differentiation in eastern Pacific blennioid fishes. Proceedings of the Royal Society of London Series B Biological Sciences 268, 1931-1936.

Rohfritsch, A. and Borsa, P. (2005) Genetic structure of Indian scad mackerel Decapterus russelli: Pleistocene vicariance and secondary contact in the Central IndoWest Pacific Seas. Heredity 95, 315-326.

Roldan, M.I., Perrotta, R.G., Cortey, M. and Pla, C. (2000) Molecular and morphologic approaches to discrimination 
of variability patterns in chub mackerel, Scomber japonicus. Journal of Experimental Marine Biology and Ecology 253, 63-74.

Rosenblatt, R.H. and Waples, R.S. (1986) A genetic comparison of allopatric populations of shore fish species from the eastern and central Pacific-Ocean - dispersal or vicariance. Copeia 2, 275-284.

Rousset, F. (1997) Genetic differentiation and estimation of gene flow from Fstatistics under isolation by distance. Genetics 145, 1219-1228.

Rowe, S., Hutchings, J.A., Skjæraasen, J.E. and Bezanson, L. (2008) Morphological and behavioural correlates of reproductive success in Atlantic cod Gadus morhua. Marine Ecology Progress Series 354, 257-265.

Ryman, N. and Leimar, O. (2008) Effect of mutation on genetic differentiation among nonequilibrium populations. Evolution 62, 2250-2259.

Ryman, N., Palm, S., Andre, C. et al. (2006) Power for detecting genetic divergence: differences between statistical methods and marker loci. Molecular Ecology 15, 2031-2045.

Sadovy, Y. and Liu, M. (2008) Functional hermaphroditism in teleosts. Fish and Fisheries 9, 1-43.

Sarvas, T.H. and Fevolden, S.E. (2005) Pantophysin (Pan I) locus divergence between inshore $v$. offshore and northern v. southern populations of Atlantic cod in the north-east Atlantic. Journal of Fish Biology 67, 444469.

Schwartz, M.K., Luikart, G. and Waples, R.S. (2007) Genetic monitoring as a promising tool for conservation and management. Trends in Ecology \& Evolution 22, 2533.

Selkoe, K.A., Henzler, C.M. and Gaines, S.D. (2008) Seascape genetics and the spatial ecology of marine populations. Fish and Fisheries 9, 363-377.

Shapiro, D.Y. (1984) Sex reversal and sociodemographic processes in coral reef fishes. In: Fish Reproduction: Strategies and Tactics (eds G.W. Potts and R.J. Wootton). Academic press, London, pp. 103-118.

Shulman, M.J. (1998) What can population genetics tell us about dispersal and biogeographic history of coral-reef fishes? Australian Journal of Ecology 23, 216-225.

Shulman, M.J. and Bermingham, E. (1995) Early-life histories, ocean currents, and the population-genetics of Caribbean reef fishes. Evolution 49, 897-910.

Slatkin, M. (2005) Seeing ghosts: the effect of unsampled populations on migration rates estimated for sampled populations. Molecular Ecology 14, 67-73.

Stefanni, S. and Thorley, J.L. (2003) Mitochondrial DNA phylogeography reveals the existence of an Evolutionarily Significant Unit of the sand goby Pomatoschistus minutus in the Adriatic (Eastern Mediterranean). Molecular Phylogenetics and Evolution 28, 601-609.

Stefanni, S., Gysels, E.S., Volckaert, F.A.M. and Miller, P.J. (2003) Allozyme variation and genetic divergence in the sand goby, Pomatoschistus minutus (Teleostei : Gobiidae).
Journal of the Marine Biological Association of the United Kingdom 83, 1143-1149.

Turner, T.F., Wares, J.P. and Gold, J.R. (2002) Genetic effective size is three orders of magnitude smaller than adult census size in an abundant, estuarine-dependent marine fish (Sciaenops ocellatus). Genetics 162, 1329 1339.

Van Herwerden, L., Choat, J.H., Dudgeon, C.L., Carlos, G., Newman, S.J., Frisch, A. and Van Oppen, M. (2006) Contrasting patterns of genetic structure in two species of the coral trout Plectropomus (Serranidae) from east and west Australia: introgressive hybridisation or ancestral polymorphisms. Molecular Phylogenetics and Evolution 41, 420-435.

Volff, J.N. (2005) Genome evolution and biodiversity in teleost fish. Heredity 94, 280-294.

Von Bertalanffy, L. (1938) A quantitative theory of organic growth Inquiries on growth laws. II. Human Biology 10, 181-213.

Waples, R.S. (1987) A multispecies approach to the analysis of gene flow in marine shore fishes. Evolution 41, 385-400.

Waples, R.S. (1998) Separating the wheat from the chaff: patterns of genetic differentiation in high gene flow species. Journal of Heredity 89, 438-450.

Ward, R.D. and Elliott, N.G. (2001) Genetic population structure of species in the South East Fishery of Australia. Marine E Freshwater Research 52, 563-573.

Ward, R.D., Woodwark, M. and Skibinski, D.O.F. (1994) A comparison of genetic diversity levels in marine, freshwater, and anadromous fishes. Journal of Fish Biology 44, 213-232.

Warner, R.R. (1975) Adaptive significance of sequential hermaphroditism in animals. The American Naturalist 109, 61-82.

Warner, R.R. (1988a) Sex change in fishes - hypotheses, evidence, and objections. Environmental Biology of Fishes 22, 81-90.

Warner, R.R. (1988b) Sex change and the size-advantage model. Trends in Ecology \& Evolution 3, 133-136.

Watts, R.J. and Johnson, M.S. (2004) Estuaries, lagoons and enclosed embayments: habitats that enhance population subdivision of inshore fishes. Marine and Freshwater Research 55, 641-651.

Weir, B.S. and Cockerham, C.C. (1984) Estimating Fstatistics for the analysis of population-structure. Evolution 38, 1358-1370.

Werner, F.E., Cowen, R.K. and Paris, C.B. (2007) Coupled biological and physical models: present capabilities and necessary developments for future studies of population connectivity. Oceanography 20, 54-69.

Williams, L.M. and Oleksiak, M.F. (2008) Signatures of selection in natural populations adapted to chronic pollution. BMC Evolutionary Biology 8, 282.

Wilson, A.B. (2006) Genetic signature of recent glaciation on populations of a near-shore marine fish species 
(Syngnathus leptorhynchus). Molecular Ecology 15, 1857 1871.

Wright, S. (1951) The genetical structure of populations. Annals of Eugenics 15, 323-354.

Wright, S. (1978) Evolution and the Genetic of Populations. Vol. 4. Variability Within and Among Natural Populations. University of Chicago press, Chicago.

\section{Supporting Information}

Additional Supporting Information may be found in the online version of this article:

Table S1. Correlation tests of continuous (Pearson) and binary variables (Spearman) with the first two axes of a PCO analysis carried out with a subset of data containing larval duration.

Table S2. Analysis of variance testing for differences in Hedrick's adjusted (a,b) and non-adjusted (c,d) $F_{\mathrm{ST}} /\left(1-F_{\mathrm{ST}}\right)$ among reproductive modes (gonochorists vs. protogynous vs. protandrous) for allozymes (a,c) and microsatellites (b,d).

Table S3. Correlations between $F_{\mathrm{ST}} /\left(1-F_{\mathrm{ST}}\right)$ and continuous (Pearson) and binary variables (Spearman) presented in Table 1.

Figure S1. Relationships between $F_{\mathrm{ST}} /\left(1-F_{\mathrm{ST}}\right)$ and the two principal coordinates (PCO1, PCO2) for (a) mitochondrial and (b) nuclear DNA. $R$ is the correlation coefficient. Trend lines are shown for significant correlations.

Please note: Wiley-Blackwell are not responsible for the content or functionality of any supporting materials supplied by the authors. Any queries (other than missing material) should be directed to the corresponding author for the article. 